Sharif University of Technology
Scientia Iranica
Transactions E: Industrial Engineering
http://scientiairanica.sharif.edu
IRAN I CA

\title{
Sustainable supplier selection and order allocation: An integrated delphi method, fuzzy TOPSIS, and multi-objective programming model
}

\author{
M. Rabieh ${ }^{a, *}$, A. Fadaei Rafsanjani ${ }^{a}$, L. Babaei ${ }^{a}$, and M. Esmaeili ${ }^{b}$ \\ a. Faculty of Management and Accounting, Shahid Beheshti University, Tehran, Iran. \\ b. Industrial Management, Faculty of Management and Accounting, Allameh Tabataba'i University, Tehran, Iran.
}

Received 25 September 2017; received in revised form 18 March 2018; accepted 16 July 2018

\author{
KEYWORDS \\ Sustainable supplier \\ selection; \\ Order allocation; \\ Fuzzy TOPSIS; \\ Multi-objective \\ programming; \\ Epsilon constraint \\ method; \\ Weighted sum \\ method.
}

\begin{abstract}
The purpose of the current study is to select suppliers and determine their order allocation in a way that the performance of the sustainability of the supply process gets optimized on the whole. In this research, after reviewing the literature and investigating the supply chain of the case study (Iran Khodro's supply chain) through Delphi method, a set of evaluation criteria related to the performance of the suppliers in economic, social, and environmental terms was identified. In the next stage, by using the identified criteria, the multi-objective mathematical integer programming was presented to solve the problems of supplier selection and order allocation. The suggested mathematical programming in this research is designed to be multi-product, single-period, and multiple sourcing. Fuzzy TOPSIS method is applied to calculate the qualitative parameters that are used in the suggested mathematical programming. Ultimately, the mathematical model suggested in the research is solved by two methods, i.e., epsilon constraint method and weighted sum method. Moreover, the Total Value of Sustainable Purchasing (TVSP) is calculated for both cases. The comparison of these two methods indicates that, in this research, the results of the weighted sum method are more efficient than those of the epsilon constraint method.

(C) 2019 Sharif University of Technology. All rights reserved.
\end{abstract}

\section{Introduction}

The sustainability of the supply chain has received great attention in the earlier decade-both in the domain of academic researches and in practice. Because of the rise of global competition and the pressure exerted by different stakeholders in the supply chain, especially governmental lawmakers and social and environmental activists, most organizations are required to consider sustainability in their performance. Com-

*. Corresponding author.

E-mail address: m_rabieh@sbu.ac.ir (M. Rabieh)

doi: $10.24200 /$ sci.2018.5254.1176 bining two concepts of sustainable development and supply chain management makes sense under the management of a sustainable supply chain [1]. Elkington was the first who coined "the Triple Bottom Line" (TBL) to define sustainability [2]. The aforementioned phrase consists of economic, social, and environmental terms. Hassini et al. defined sustainability as the ability to manage an organization by considering longterm purposes that are related to economy, environment, and society [3]. The World Commission on Environment and Development takes sustainable development as a kind of development that meets the needs of the present without compromising the ability of future generations to meet their own needs [4]. The cooperation of all members, including suppliers, 
manufacturers, distributors, retailers, and managers, is necessary to access and maintain sustainability in the supply chain. Therefore, supplier selection and evaluation as significant elements in the supply chain (according to the criterion of sustainability) play a key role in the sustainability of the supply chain. MultiCriteria Decision-Making (MCDM) and various exact and efficient heuristic methodologies have been used to solve the Supplier Selection Problem (SSP) in the literature [5]. The basic questions that are used in the literature for decision-making models are as follows: How many suppliers are need? Which suppliers should be selected? What is the optimal ordering policy for each supplier [6]? Cooperation with suppliers with a good status in economic, social, and environmental terms can enhance the performance of the supply chain in respect of sustainability. In addition, it sets the scene for moving towards sustainable development [7]. Accordingly, organizations are bound to apply new indices to ensure sustainable development-a case that is not taken into consideration appropriately. These indices are known to be indices of sustainability that result in the sustainability of the system. The indices of sustainability, in a general classification, are categorized into economic, social, and environmental indices. The aforementioned indices highlight both the relationship among human beings and the relationship between human being and environment on the path toward development and progress. Sustainability will be taken into account in most fields such as agriculture, engineering, construction, production, and designing. The point to be considered is that the sustainability of the system is the intersection of economic, social, and environmental indices [8].

The purpose of the current study is to select suppliers and determine their order allocation in a way that the performance of the sustainability of the supply process gets optimized on the whole. In this research, the indices of sustainability with regard to the triple bottom line (economic, environmental, and social) will be taken into consideration for selecting the supplier of auto parts in the supply chain of Iran Khodro company. In the integrated model suggested in this research, firstly, the criteria for evaluating the performance of the suppliers are identified through Delphi method. Then, according to the given and approved criteria, a multiobjective mathematical integer programming model will be developed. By using real data from the supply chain of the case study, the aforementioned model will be solved. The solution process is implemented through the epsilon constraint method and the weighted sum method.

The structure of the present paper is as follows: the second section provides a review of the theoretical background and relevant literature which deal with sustainable supplier selection. The methodology of the research including the Delphi technique, mathematical modeling, and solution processes is presented in the third section. Sensitivity analysis and management applications are given in the fourth section. Finally, the fifth section consists of the conclusion and recommendations for further research.

\section{Review of literature: Sustainable supplier selection}

The sustainable supplier selection can be considered as the same classical supplier selection problem in which social and environmental criteria alongside economic ones are taken into account for selecting and evaluating the suppliers [9]. Sustainable supplier selection as a critical and significant decision in the supply chain can be influential in the extent of overall sustainability in the given supply chain [10]. Sustainable supplier selection necessitates evaluating the performance of the suppliers according to a combination of evaluation criteria of the triple bottom line. The literature related to sustainable supplier selection will be reviewed in terms of sustainable supplier selection criteria and sustainable supplier selection methods.

\subsection{Sustainable supplier selection criteria}

Most studies done in the area of sustainable supplier selection have focused solely on environmental and economic aspects [11-13]. In recent years, some researchers have endeavored to take into account the social aspect of sustainability either separately or parallel with the other aspects in supplier selection problem [14-18]. Table 1 presents the criterion for supplier evaluation done in the most important recent researches. The aforementioned studies consist of cases in which all of the three aspects of sustainability have been taken into consideration for evaluation.

As can be observed from the given table, price/cost, quality, and delivery are the most important economic criteria. It should be noted that pollution control, green design, environmental management system, and environmental capabilities are among the most significant environmental criteria. Lastly, work safety and labor health and the rights of stakeholders are considered to be the most dominant social criteria, which are used in the area of sustainable supplier selection.

The other point to be highlighted is that although many have been published about supplier selection, the studies done about sustainable supplier selection are not adequate. According to the investigations carried out, it seems that environmental indices in the form of greenness have been used more in recent years to evaluate performance and select suppliers. However, economic, social, and environmental indices have been taken into account rather less simultaneously 
Table 1. Summary of sustainable supplier selection evaluation criterion and their references.

\begin{tabular}{|c|c|c|c|c|c|c|c|c|c|c|c|c|c|c|c|c|}
\hline & \multicolumn{15}{|c|}{ References } \\
\hline & & {$[7]$} & [10] & [14] & [15] & {$[17]$} & [18] & [19] & [20] & [21] & {$[22]$} & [23] & {$[24]$} & {$[25]$} & [26] & [27] \\
\hline \multirow{14}{*}{ 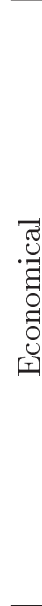 } & Price/cost & $\sqrt{ }$ & $\sqrt{ }$ & $\sqrt{ }$ & $\sqrt{ }$ & $\sqrt{ }$ & $\sqrt{ }$ & $\sqrt{ }$ & $\sqrt{ }$ & $\sqrt{ }$ & $\sqrt{ }$ & $\sqrt{ }$ & $\sqrt{ }$ & $\sqrt{ }$ & - & $\sqrt{ }$ \\
\hline & Quality & $\sqrt{ }$ & $\sqrt{ }$ & $\sqrt{ }$ & $\sqrt{ }$ & $\sqrt{ }$ & - & $\sqrt{ }$ & $\sqrt{ }$ & $\sqrt{ }$ & $\sqrt{ }$ & $\sqrt{ }$ & $\sqrt{ }$ & $\sqrt{ }$ & $\sqrt{ }$ & $\sqrt{ }$ \\
\hline & Technology & $\sqrt{ }$ & - & - & $\sqrt{ }$ & $\sqrt{ }$ & $\sqrt{ }$ & $\sqrt{ }$ & $\sqrt{ }$ & - & - & - & $\sqrt{ }$ & - & $\sqrt{ }$ & $\sqrt{ }$ \\
\hline & Delivery & $\sqrt{ }$ & $\sqrt{ }$ & $\sqrt{ }$ & - & $\sqrt{ }$ & - & $\sqrt{ }$ & - & $\sqrt{ }$ & $\sqrt{ }$ & - & $\sqrt{ }$ & $\sqrt{ }$ & - & $\sqrt{ }$ \\
\hline & Services & $\sqrt{ }$ & $\sqrt{ }$ & $\sqrt{ }$ & $\sqrt{ }$ & - & $\sqrt{ }$ & - & - & - & $\sqrt{ }$ & - & $\sqrt{ }$ & $\sqrt{ }$ & - & - \\
\hline & Relationship & - & - & - & - & - & - & - & - & - & $\sqrt{ }$ & - & - & - & - & - \\
\hline & Flexibility & $\sqrt{ }$ & - & - & $\sqrt{ }$ & - & - & $\sqrt{ }$ & $\sqrt{ }$ & - & - & - & $\sqrt{ }$ & $\sqrt{ }$ & - & - \\
\hline & Production facilities and capacity & - & - & - & - & - & - & - & $\sqrt{ }$ & - & - & - & $\sqrt{ }$ & - & $\sqrt{ }$ & - \\
\hline & Financial capability & $\sqrt{ }$ & - & - & - & - & $\sqrt{ }$ & - & $\sqrt{ }$ & - & - & - & $\sqrt{ }$ & - & - & - \\
\hline & Organization and management & $\sqrt{ }$ & - & - & - & - & - & - & $\sqrt{ }$ & - & - & - & - & - & - & $\sqrt{ }$ \\
\hline & Number of shipmer & - & - & - & - & - & - & - & $\sqrt{ }$ & - & - & - & - & - & - & - \\
\hline & Reliability & - & - & - & - & - & - & - & $\sqrt{ }$ & - & - & - & - & - & - & - \\
\hline & Geographical location & - & - & - & - & - & - & - & - & - & - & - & - & - & $\sqrt{ }$ & - \\
\hline & Loyalty & - & - & - & - & - & $\sqrt{ }$ & - & - & - & - & - & - & - & - & - \\
\hline \multirow{22}{*}{ 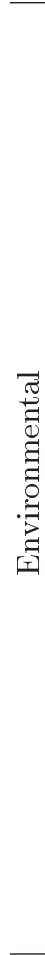 } & Environmental cos & - & - & - & - & - & - & $\sqrt{ }$ & $\sqrt{ }$ & - & - & $\sqrt{ }$ & $\sqrt{ }$ & - & - & - \\
\hline & Green design & - & - & - & - & $\sqrt{ }$ & - & $\sqrt{ }$ & $\sqrt{ }$ & - & $\sqrt{ }$ & - & $\sqrt{ }$ & $\sqrt{ }$ & - & - \\
\hline & Environmental management system & - & $\sqrt{ }$ & $\sqrt{ }$ & $\sqrt{ }$ & $\sqrt{ }$ & $\sqrt{ }$ & $\sqrt{ }$ & $\sqrt{ }$ & - & $\sqrt{ }$ & - & $\sqrt{ }$ & $\sqrt{ }$ & - & - \\
\hline & Environmental capability & $\sqrt{ }$ & $\sqrt{ }$ & $\sqrt{ }$ & - & - & - & - & $\sqrt{ }$ & $\sqrt{ }$ & $\sqrt{ }$ & - & $\sqrt{ }$ & - & - & $\sqrt{ }$ \\
\hline & Green R\&D & - & - & - & - & - & - & $\sqrt{ }$ & $\sqrt{ }$ & - & - & - & $\sqrt{ }$ & - & - & - \\
\hline & Pollution control & - & - & - & $\sqrt{ }$ & $\sqrt{ }$ & $\sqrt{ }$ & - & $\sqrt{ }$ & $\sqrt{ }$ & $\sqrt{ }$ & - & - & - & $\sqrt{ }$ & - \\
\hline & Green products & - & - & - & - & - & - & - & $\sqrt{ }$ & - & - & - & $\sqrt{ }$ & $\sqrt{ }$ & - & - \\
\hline & Resource consumption & - & - & - & $\sqrt{ }$ & $\sqrt{ }$ & - & - & $\sqrt{ }$ & - & - & - & - & - & - & - \\
\hline & Green packaging & - & - & - & - & - & - & - & - & - & - & - & $\sqrt{ }$ & - & - & - \\
\hline & Energy efficiency & - & - & - & - & - & - & - & - & $\sqrt{ }$ & - & - & - & - & - & - \\
\hline & Environmental fines & - & - & - & - & - & - & - & - & $\sqrt{ }$ & - & - & - & - & - & - \\
\hline & Ozone depleting chemicals & - & - & - & - & - & - & - & $\sqrt{ }$ & - & - & - & - & - & - & - \\
\hline & Waste management system & - & - & - & - & - & - & - & - & - & - & - & $\sqrt{ }$ & - & - & - \\
\hline & Recycling & - & - & - & - & - & - & - & $\sqrt{ }$ & - & - & - & - & - & - & - \\
\hline & Greenhouse $e$ & - & - & - & - & - & $\sqrt{ }$ & - & - & - & - & - & - & - & - & - \\
\hline & Green warehousing & - & - & - & - & - & - & - & - & - & - & - & - & $\sqrt{ }$ & - & - \\
\hline & Green transportation & - & - & - & - & - & - & - & - & - & - & - & - & $\sqrt{ }$ & - & - \\
\hline & Green techno & - & - & - & - & - & - & - & - & - & - & - & - & $\sqrt{ }$ & - & - \\
\hline & Environmental performance & - & - & - & - & - & - & - & - & - & - & - & - & - & $\sqrt{ }$ & - \\
\hline & Green image & - & - & - & - & - & - & - & - & - & - & - & - & - & $\sqrt{ }$ & $\sqrt{ }$ \\
\hline & Green competencies & - & - & - & - & - & - & - & - & - & - & - & - & - & $\sqrt{ }$ & - \\
\hline & Green management & - & - & - & - & - & - & - & - & - & - & - & $\sqrt{ }$ & - & - & - \\
\hline \multirow{14}{*}{ 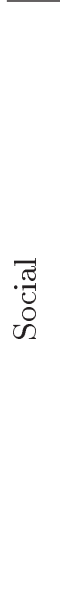 } & Respect for the policy & - & - & - & - & - & - & - & $\sqrt{ }$ & - & $\sqrt{ }$ & - & - & - & - & - \\
\hline & The rights of employees & - & - & - & - & - & - & - & $\sqrt{ }$ & $\sqrt{ }$ & - & - & $\sqrt{ }$ & $\sqrt{ }$ & - & - \\
\hline & The rights of stakeholders & - & $\sqrt{ }$ & $\sqrt{ }$ & $\sqrt{ }$ & - & - & - & $\sqrt{ }$ & - & $\sqrt{ }$ & $\sqrt{ }$ & $\sqrt{ }$ & - & - & - \\
\hline & Work safety and labor health & - & $\sqrt{ }$ & $\sqrt{ }$ & $\sqrt{ }$ & $\sqrt{ }$ & $\sqrt{ }$ & - & $\sqrt{ }$ & - & $\sqrt{ }$ & $\sqrt{ }$ & - & $\sqrt{ }$ & $\sqrt{ }$ & - \\
\hline & Information disclosure & - & - & - & - & - & - & - & $\sqrt{ }$ & - & $\sqrt{ }$ & - & $\sqrt{ }$ & - & - & - \\
\hline & Social responsibility & $\sqrt{ }$ & - & - & - & - & - & - & - & $\sqrt{ }$ & - & - & - & - & - & - \\
\hline & Employment practices & - & - & - & - & $\sqrt{ }$ & - & - & - & - & - & - & - & - & - & - \\
\hline & Local communities influence & - & - & - & - & $\sqrt{ }$ & - & - & - & - & - & - & - & - & - & - \\
\hline & stakeholders influence & - & - & - & - & $\sqrt{ }$ & - & - & - & - & - & - & - & - & - & - \\
\hline & philanthropic causes & - & - & - & - & - & - & - & - & $\sqrt{ }$ & - & - & - & - & - & - \\
\hline & Training & - & - & - & - & - & $\sqrt{ }$ & - & - & - & $\sqrt{ }$ & - & - & - & - & - \\
\hline & Supportive activities & - & - & - & - & - & - & - & - & - & - & - & - & $\sqrt{ }$ & - & - \\
\hline & Employment practices & - & - & - & - & - & - & - & - & - & - & - & - & - & $\sqrt{ }$ & - \\
\hline & Occupational health and safety & - & - & - & - & - & $\sqrt{ }$ & - & - & - & - & - & $\sqrt{ }$ & - & - & - \\
\hline
\end{tabular}


in the area of sustainable development. In this regard, previous studies suffer from some weak points, the resolution of which seems to be a necessity. For example, in some studies, only economic and environmental indices have been considered, while, according to the definition of sustainability, all indices including the economic, environmental, and social ones must be highlighted [10].

\subsection{Sustainable supplier selection method}

Over recent years, researchers have utilized different methods to resolve the supplier selection problem in a sustainable environment. In 2013, Seuring reviewed 306 papers about sustainable supply chain and green supply chain published between 1990 and 2010. He reached the conclusion that, in the aforementioned time period, only 36 papers were quantitative and the rest were qualitative. Therefore, there remains the necessity of more qualitative research in this area. The findings of this research indicate that, due to the difficulty underlying the modeling of social impacts, the given index has not been taken into account sufficiently in quantitative models [28]. Qualitative approaches adopted in some of the most important recent researches in this area are summarized in Table 2 .

One of the efficient methods to resolve a sustainable supplier selection problem is mathematical modeling which has been used in some of the mentioned researches in Table 2. Since the current study concentrates on mathematical modeling, the characteristics of some of the multi-objective models in the area of sustainable and green supplier selection will be presented in what follows. Mafakheri et al. (2011) adopted a two-phase approach to explore supplier selection problem and determine the amount of order allocation. In the first phase, the supplier evaluation criteria (price/cost, delivery, quality, and environmental performance) and their sub-criteria are defined based on AHP method. Then, the amount of order allocation to each supplier will be specified by a multi-objective linear mathematical model. The objective functions of the mentioned model consist of minimization of total cost and maximization of total value in the supply process. Demand, production capacity, and stock levels at the end of each period are among the constraints of the model [33]. In the research conducted by Shaw et al. (2012), the supplier selection problem in the supply chain was tackled with the amount of carbon emission. In their study, AHP method was used to determine the weight of the criteria. Then, a multi-objective linear mathematical fuzzy model was presented. The mathematical model of this research included four objective functions, namely minimization of cost, total number of returned goods due to lack of quality, delivery with delay and greenhouse gases emission. In addition, the constraints of demand, production capacity of the suppliers, budget, and the maximum amount of carbon emission were taken into consideration in this model [34]. Afshar Bakeshlou et al. (2017) developed a multi-objective fuzzy linear programming model for a green supplier selection problem. They used a set of evaluation criteria in five major clusters including cost, quality, service, technology capability, and environmental criteria. They also applied a hybrid fuzzy MODM method to solve the proposed model. The objective functions of their model consist of purchase cost, total quality, service level, technology capability, and environmental function [35].

Nazari-Shirkouhi et al. (2013) presented an interactive two-phase Fuzzy Multi-Objective Linear Programming (FMOLP) model to solve a supplier selection problem under multi-price and multi-product conditions. Their model minimized total purchasing and ordering costs, number of defective units, and late delivered units ordered from suppliers [36]. Kannan et al. (2013) rated the suppliers with fuzzy TOPSIS method in order to solve green supplier selection problem and determine their allocation. Then, they drew from multi-objective linear mathematical model to specify the allocation to each of them. The objective functions of this model comprise minimization of total cost and maximization of total desirability function in the supply process. The constraints of this model are as follows: demand, capacity, and the maximum number of acceptable defective goods [37]. In the study done by Trapp and Sarkis (2016), a linear zero-one optimization programming model was presented such that suppliers selection and development on the one hand and sustainability considerations on the other were examined at the same time. The objective function of this model includes the maximization of the performance of total sustainability in the supply process. On the other hand, the production capacity, the minimum and maximum number of suppliers, quality, delivery, training cost, and price are known to be the constraints of this model [32]. In the model presented by Azadnia et al. (2015), firstly, a set of evaluation criteria related to all three aspects of sustainability was established by using opinions of company's experts and existing criteria in the literature. Next, the weight of the criteria was calculated based on FAHP approach. After that, a multi-objective mathematical model was presented to solve the sustainable supplier selection problem and determine their order allocation in a multi-product and multi-period case. The objective functions of this model consist of the minimization of total cost and maximization of qualitative economic advantage, environmental advantage, and social advantage. The constraints of the model include production capacity, warehouse space, and stock level at the end of the period [18]. 
Table 2. Summary of methodologies adopted in various researches about sustainable supplier selection.

\begin{tabular}{|c|c|c|}
\hline References & Methodologies & Issues \\
\hline$[7]$ & Fuzzy ANP & Sustainable supplier selection with incomplete information \\
\hline [10] & Fuzzy inference system & Sustainable supplier selection \\
\hline [14] & $\begin{array}{l}\text { Artificial Neural Network (ANN) } \\
\text { and MADA methods }\end{array}$ & Sustainable supplier selection \\
\hline$[15]$ & Grey system and rough set & Sustainability into supplier selection \\
\hline$[17]$ & Fuzzy TOPSIS & $\begin{array}{l}\text { Measuring sustainability } \\
\text { performance of a supplier based } \\
\text { on triple bottom line approach }\end{array}$ \\
\hline [18] & $\begin{array}{l}\text { FAHP and multi-objective } \\
\text { mathematical model }\end{array}$ & $\begin{array}{l}\text { Sustainable supplier selection } \\
\text { and order lot-sizing }\end{array}$ \\
\hline [19] & Rough set theory and DEA & Sustainability focused performance evaluation for suppliers \\
\hline [20] & DEA & Sustainable supplier performance evaluation and selection \\
\hline$[21]$ & $\begin{array}{l}\text { Bayesian framework and Monte Carlo } \\
\text { Markov Chain (MCMC) }\end{array}$ & Supplier selection for sustainable operations \\
\hline$[22]$ & DEMATEL-TOPSIS & A decision support tool for sustainable supplier selection \\
\hline [23] & Robust dynamic DEA & Evaluating and ranking sustainable suppliers \\
\hline [24] & AHP-VIKOR & Sustainable supplier selection and evaluation \\
\hline$[25]$ & $\begin{array}{c}\text { Fuzzy TOPSIS - Fuzzy } \\
\text { Preference Programming (FPP) }\end{array}$ & Sustainable supplier selection \\
\hline$[26]$ & Fuzzy inference system & Sustainable supplier performance scoring \\
\hline [29] & Fuzzy ART algorithm & A categorization method for supplier evaluation and selection \\
\hline [30] & Multi-objective mathematical model & Supplier selection model for social responsible supply chain \\
\hline [31] & Grey DEMATEL & Improving SSCM via supplier related decisions \\
\hline$[32]$ & Integer programming & $\begin{array}{l}\text { Optimization model for supplier } \\
\text { selection and development taking } \\
\text { sustainability consideration }\end{array}$ \\
\hline
\end{tabular}




\section{Research methodology}

\subsection{Case study}

Automobile is one of those products that has a great deal of interaction with the environment and people throughout the course of its life cycle and at the time of usage. Therefore, apart from economic considerations, the social and environmental aspects must be taken into account in all stages of its designing and development. Considering the rise of pressures and the concerns of governments and non-governmental organizations, the given issue has achieved greater importance day by day. Furthermore, it will turn into one of the customer requirements for satisfaction with the products of an organization in the future. The automobile supply chain in Iran is a case in point. Accordingly, the policymakers in this area are fully aware of social and environmental issues apart from economic interests.

The supply chain of Iran Khodro Company is the case study of the present research. The management of the supply system of parts needed in this chain and correspondence with the suppliers are borne by Sapco Company. As a matter of fact, Sapco Company assumes responsibility for technical designing and supplying the parts, which are required by Iran Khodro Company. The mission of this company is to provide raw material, parts, and automobile accessories for the Industrial Group of Iran Khodro and foreign and domestic target markets. This is done through efficient management of the supply process-from designing to assembly and identifying competitive advantages in the supply network to improving them to global levels, all of which are aimed at the achievement of the strategic purposes of Iran Khodro Group. Sapco Company cooperates with more than 550 domestic and foreign suppliers at the moment. In addition, Sapco provides the Industrial Group of Iran Khodro with the raw material, parts, and automobile accessories. The responsibilities in the areas of production and aftersale services are shouldered by the same company. In Sapco Company, all orderings are done based on Kanban system. Kanban card volume is a coefficient of container quantity. The number of running Kanban cards is specified in accordance with the supply waiting time and the performance of the suppliers for each part. In order to conduct the present research, 31 parts used in the engine of four car types made by Iran Khodro Company were selected. These parts are manufactured and provided by 45 suppliers. The purpose of the current study is to resolve the sustainable supplier selection problem and determine the optimal order allocation in a way that the total sustainability of the supply process gets optimized. To achieve this goal, first and foremost, the appropriate criteria for sustainable supplier selection in the case study company are identified. Then, the mathematical model and competent suppliers of each intended part will be selected. Lastly, the allocation to each of them will be specified.

In fact, despite the emphasis on sustainability in recent years, qualitative researches in this area are not enough. It needs to be explained that in most of the previous studies, only economic and environmental dimensions are considered in sustainable or green supplier selection, and social aspects of sustainability are somewhat taken for granted at the same time. In this regard and in order to fill the research gap, the present study is important. Therefore, compared to previous researches, the strength of this research is using real data and applying a new set of criteria that have not been applied in similar studies so far. They include PPM, C/100, deviation from the target price, and quality index of supply.

\subsection{The suggested integrated model}

In the present research, apart from investigating the theoretical background and reviewing the literature, the research gaps on the one hand and criteria and methods used for sustainable supplier selection problem on the other hand are presented. At the same time, in order to get familiarized with the criteria and methods used to select the supplier in the supply chain of Iran Khodro, several interviews with the experts and professionals of the case study company (Sapco Company) were conducted. Additionally, the method for selecting the suppliers was examined. After specifying the parts and the potential suppliers of each part, the theoretical background and the literature related to sustainable supplier selection problem helped identify a set of selection and evaluation criteria. Then, the Delphi method was utilized to screen the given criteria and rate them. These were based on the opinion of the experts in the company. Afterwards, the criteria drawn from the Delphi method were taken into account as three major indices of sustainability. Fuzzy TOPSIS method was used to specify the weight and value of some of the parameters (qualitative parameters whose numerical data did not exist based on the evaluations of the company). Next, the mathematical model was solved, whose findings are presented. The suggested research framework is given in Figure 1.

\subsubsection{Identifying sustainable supplier selection criteria through the delphi method}

Delphi method is a multi-stage technique to collect data in cases where the subject matter is abstract. Written responses are given priority over assembling a group of experts. The purpose of Delphi method is to reach consensus through numerical estimations with the possibility of open discussion and revision of opinions at the same time [38]. The participants of Delphi are experts, specialists, or panelists. They need 


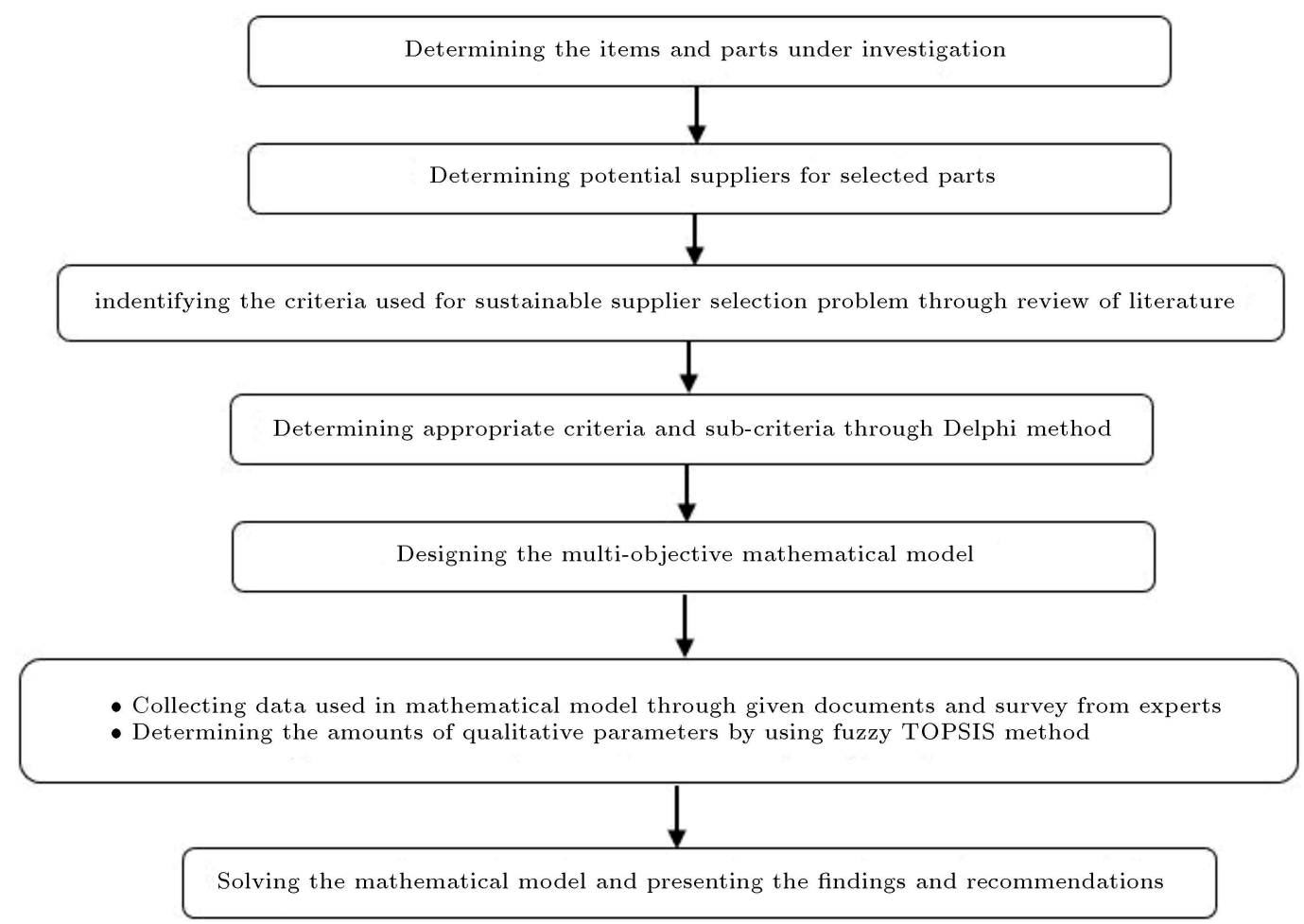

Figure 1. Stages of the research.

four qualities: knowledge and experience in the subject matter, tendency, adequate time to take part in the survey, and efficient communicative skills. It should be noted that panelists' capabilities, panel size, and the selection method are among the key parameters of the study [39]. In the Delphi method utilized in the current research, 10 persons were selected as experts. They were required to rate 32 criteria about supplier selection in the questionnaire based on their significance. The criteria given in the Delphi questionnaire were chosen according to the theoretical bases and experts' opinions in the company. In this questionnaire, a fivechoice Likert scale was used. Furthermore, Kendall's coefficient of concordance was applied to determine the extent of consensus among the members of the panel in the present research. Accordingly, a consensus among the experts resulted after conducting three rounds; consequently, the final criteria for sustainable supplier selection were specified. These criteria and their definitions are given in Tables 3 and 4 .

\subsubsection{Mathematical model of the problem}

As shown in Table 2, financial criteria are essentially categorized into two groups: cost and non-cost. Concerning non-cost economic criteria, quality and production capacity are taken to be the constraints of the model and the rest will be considered in the objective function. In addition, all environmental and social criteria are given in the objective function. Since annual evaluations are conducted, there are numerical data in the case study company for some of the criteria that have been used in the model. Furthermore, for those which are qualitative, rating will be done through fuzzy TOPSIS method. Such qualitative criteria consist of the level of technology, implementing the system of environmental management, green design and production, responsiveness and observation of rules related to work safety, and labor health. In order to determine the score of each supplier based on the given qualitative criteria and the judgment of the company's experts, a fuzzy TOPSIS questionnaire was developed. After distributing this questionnaire to them, they were required to evaluate the performance of each of these suppliers with fuzzy numbers in terms of the given qualitative criteria.

The mathematical model suggested for this research is single-period and multi-product. The problem will be modeled for a set of parts used in four types of finished products (automobile).

\section{Assumptions of the model and conditions of the problem}

In order to formulate the mathematical model for the sustainable supplier selection problem, the following assumptions are taken into account:

1. Demand for each part is fully met. In other words, shortage of any parts is not allowable;

2. Parameters of production capacity and demand are 
Table 3. Selected economic criteria and sub-criteria for sustainable supplier selection and evaluation

\begin{tabular}{|c|c|c|c|}
\hline \multicolumn{4}{|c|}{ Cost economic criteria } \\
\hline Criteria & Sub-criteria & Type & Definition \\
\hline $\begin{array}{l}\text { Deviation from } \\
\text { target price }\end{array}$ & - & Negative & $\begin{array}{l}\text { Difference between the price offered by each } \\
\text { supplier and the target price. }\end{array}$ \\
\hline Guarantee cost & - & Negative & $\begin{array}{l}\text { The cost that is paid for solving the problem of } \\
\text { defective parts. }\end{array}$ \\
\hline \multicolumn{4}{|c|}{ Non-cost economic criteria } \\
\hline Criteria & Sub-criteria & Type & Definition \\
\hline \multirow{3}{*}{ Quality } & PPM production line ${ }^{\mathrm{a}}$ & Negative & $\begin{array}{l}\text { Qualitative index related to the number of } \\
\text { returned parts. }\end{array}$ \\
\hline & & & \\
\hline & $\mathrm{C} / 100$ index $^{\mathrm{b}}$ & Negative & $\begin{array}{l}\text { Qualitative index related to the number of } \\
\text { returned parts after sales. }\end{array}$ \\
\hline \multirow{3}{*}{$\begin{array}{l}\text { Delivery } \\
\text { performance }\end{array}$} & Stoppage of production line & Negative & Total time stops the production line of the OEM. \\
\hline & Kanban amount delay & Negative & $\begin{array}{l}\text { Delay of the supplier at the quantity of order } \\
\text { delivery. }\end{array}$ \\
\hline & Kanban time delay & Negative & Delay of the supplier at the time of order delivery. \\
\hline \multirow{2}{*}{$\begin{array}{l}\text { Level of } \\
\text { technology }\end{array}$} & Knowledge & Positive & $\begin{array}{l}\text { Supplier's level of knowledge for satisfying the } \\
\text { current and future needs in the supply chain. }\end{array}$ \\
\hline & Technical capabilities & Positive & $\begin{array}{l}\text { Supplier's level of technical capabilities for satisfying } \\
\text { the current and future needs in the supply chain. }\end{array}$ \\
\hline Delayed payment & - & Positive & $\begin{array}{l}\text { Number of days during which a supplier company } \\
\text { expects the customer company to pay the fees after } \\
\text { shipping the intended parts. }\end{array}$ \\
\hline Production capacity & - & Positive & $\begin{array}{l}\text { Maximum production power of the suppliers for } \\
\text { each part. }\end{array}$ \\
\hline \multirow[t]{2}{*}{ Operational controls } & - & Positive & $\begin{array}{l}\text { Certain measures taken to monitor and manage the } \\
\text { actions, processes, products and services at the } \\
\text { operational level of the organization. }\end{array}$ \\
\hline & $\begin{array}{l}\text { Supply volume in ratio } \\
\text { to annual total supply }\end{array}$ & Positive & $\begin{array}{l}\text { Supply percent of each supplier in ratio to the total } \\
\text { purchased parts. }\end{array}$ \\
\hline \multirow{3}{*}{$\begin{array}{l}\text { Supply qualitative } \\
\text { criteria }\end{array}$} & Power to provide raw materials & Positive & $\begin{array}{l}\text { Supplier's capabilities to provide high-quality raw } \\
\text { materials for manufacturing their own parts. }\end{array}$ \\
\hline & & & \\
\hline & $\begin{array}{l}\text { Ability to supply } \\
\text { from foreign resources }\end{array}$ & Positive & $\begin{array}{l}\text { Level of cooperation with suppliers outside the } \\
\text { country and the quality of those companies. }\end{array}$ \\
\hline Long-term relationships & - & Positive & Record of previous cooperation with the supplier. \\
\hline
\end{tabular}


Table 4. Selected environmental and social criteria and sub-criteria for sustainable supplier selection and evaluation.

\begin{tabular}{|c|c|c|c|}
\hline \multicolumn{4}{|c|}{ Environmental criteria } \\
\hline Criteria & Sub-criteria & Type & Definition \\
\hline \multirow{5}{*}{$\begin{array}{c}\text { Implementing the } \\
\text { system of environmental } \\
\text { management }\end{array}$} & Positive & Positive & Environmental management system is considered \\
\hline & & & to be a part of the whole system of management that \\
\hline & Positive & Positive & consists of organizational structure, planning activities, \\
\hline & Positive & Positive & responsibilities, actions, methods, processes, and resources \\
\hline & Positive & Positive & for providing, implementing, attaining, reviewing, and \\
\hline \multirow{2}{*}{$\begin{array}{l}\text { Green design } \\
\text { and production }\end{array}$} & Positive & Positive & $\begin{array}{l}\text { Designing a product proportionate with environmental } \\
\text { requirements. }\end{array}$ \\
\hline & Positive & Positive & Manufacturing environmental-friendly products. \\
\hline \multicolumn{4}{|c|}{ Social criteria } \\
\hline Criteria & Sub-criteria & Type & Definition \\
\hline
\end{tabular}

\begin{tabular}{|c|c|c|c|}
\hline Level of employment & - & Positive & Number of employers in the supplier company. \\
\hline $\begin{array}{l}\text { Complying with the } \\
\text { standards of work safety } \\
\text { and labor health }\end{array}$ & - & Positive & $\begin{array}{l}\text { Extent of implementing policies that support employers } \\
\text { in terms of physical and mental health in the } \\
\text { supplier company. }\end{array}$ \\
\hline
\end{tabular}

Respect for the law Positive Supplier's compliance with legal requirements.

Upholding the social rights of the workforce

Responsiveness
Organization's interest and attention towards social

Positive and human issues of the employers, apart from their financial issues.

Organization's ability to meet the interests of stakeholders (those individuals or groups that are either involved in the performance and output of the organization or influenced

Respect for the Positive by it) directly or indirectly. The stakeholders of each stakeholders' interests Positive organization vary depending on the type of that organization. Customers, employers, government, financial institutions, competitors, and the community may be included among others.

finalized exclusively for a given part. A supplier can be selected in case its order allocation is more than the allowable range that has been specified by the company. This assumption prevents very low order allocations since it is not cost effective. To this end, a percentage of the total demand for each part is specified for each supplier as the order base. The model is developed in a way that no allocation is dedicated to amounts less than the minimum order.

\section{Notations of the mathematical model}

The notations used for the mathematical model of the present research are given below:

\section{Indices of the model \\ $i \quad$ Type of part, $i=1,2, \ldots, m$; \\ $j \quad$ Number of Suppliers, $j=1,2, \ldots, n$; \\ $k \quad$ Type of finished product, $k=$ $1,2, \ldots, K$.}

Parameters of the model

$\delta_{i j} \quad$ Deviation of the price proposed by the $j$ th supplier from the target price for the $i$ th part;

$g_{i j} \quad$ Cost of guarantee for part $i$ that will be offered by supplier $j$;

$D_{i k} \quad$ Demand for part $i$ that will be used to make product type $k$; 
$C A_{i j} \quad$ Production capacity of the $j$ th supplier for the $i$ th part;

$P P M_{i j} \quad$ PPM quality index (index of returned parts) of the $j$ th supplier for the $i$ th part;

$A P P M_{i j} \quad$ PPM maximum value that is allowable for the $i$ th part;

$C_{i j} \quad \mathrm{C} / 100$ quality index (index of returned parts) of the $j$ th supplier for the $i$ th part;

$A C_{i} \quad \mathrm{C} / 100$ maximum value that is allowable for the $i$ th part;

$D L_{i j} \quad$ Score of the $j$ th supplier in delivery performance;

$T_{j} \quad$ Score of the $j$ th supplier in technology level;

$R_{j} \quad$ Score of the $j$ th supplier in payday resistance;

$C O_{j} \quad$ Score of the $j$ th supplier in operational controls;

$L R_{j} \quad$ Score of the $j$ th supplier in long-term relationships;

$C S_{j} \quad$ Score of the $j$ th supplier in quality index of supply;

$E_{j} \quad$ Score of supplier $j$ in terms of environmental criteria;

$S_{j} \quad$ Score of supplier $j$ in terms of social criteria;

$L_{i j} \quad$ Minimum percentage of demand for part $i$ that will be purchased from supplier $j$.

Decision variables

$X_{i j} \quad$ Number of part $i$ that will be purchased from supplier $j$;

$Y_{i j} \quad$ Order allocation or non-allocation to supplier $j$ to supply part $i$ (binary variable).

\section{Objective functions}

The mathematical model of the current study consists of four objective functions, which are given in Eqs. (1) to (4). Cost economic criteria will appear in the first objective function. According to the mentioned objective function, the total cost (deviation from the target price and cost of guarantee) will reach its minimum amount. Eq. (2) deals with non-cost economic criteria according to which non-cost economic performance reaches its maximum amount. In the given, the first section points to the total performance of the selected suppliers in terms of delivery performance. The following sections refer to the performance of the suppliers in technology level, payday resistance, oper- ational controls, long-term relationships, and quality index of supply, respectively. It should be noted that among non-cost economic criteria, except for delivery performance which is calculated based on the intended part, the data for all the other ones depend on the supplier. Accordingly, the formulas of the second objective function for this group of criteria are divided by the total demand. In this way, there will be an equal scale for all of them. Eq. (3) maximizes the environmental score of the whole process of supply, which results from the multiplication of the total environmental score of each supplier by the allocation amount. Eq. (4) pertains to maximizing the social performance of the whole process of sustainable supply.

\section{Constraints}

Eq. (5) refers to the constraint of demand. This constraint ensures that the demand for each part will be fulfilled. The constraints of quality (PPM and $\mathrm{C} / 100$ criteria) are given in Relations (6) and (7). According to these two constraints, only those parts that meet the minimum quality standards are selected. In Relation (8), the constraint of minimum order amount from each supplier is given. This constraint prevents the selection of suppliers with very low order amount. In addition, a supplier will be selected only in case the allocation amount is more than the minimum that has been specified. According to Relation (9), the allocation of each part to a supplier must be less than the production capacity of the respective supplier. Relations (10) and (11) demonstrate type and range of the decision variables. Relations (12) and (13) relate to the type of decision variables in the mathematical model.

$$
\begin{aligned}
\operatorname{Min} Z_{1}= & \sum_{i=1}^{m} \sum_{j=1}^{n} \delta_{i j} X_{i j}+\sum_{i=1}^{m} \sum_{j=1}^{n} g_{i j} X_{i j}-\sum_{i=1}^{m} \sum_{(1)} \\
\operatorname{Max} Z_{2}= & \sum_{i=1}^{m} \sum_{j=1}^{n} D L_{i j} . X_{i j}+\sum_{i=1}^{m} \sum_{j=1}^{n} T_{j} \frac{X_{i j}}{\sum_{k=1}^{K} D_{i k}} \\
& +\sum_{i=1}^{m} \sum_{j=1}^{n} R_{j} \frac{X_{i j}}{\sum_{k=1}^{K} D_{i k}}+\sum_{i=1}^{m} \sum_{j=1}^{n} C O_{j} \frac{X_{i j}}{\sum_{k=1}^{K} D_{i k}} \\
& +\sum_{i=1}^{m} \sum_{j=1}^{n} L R_{j} \frac{X_{i j}}{\sum_{k=1}^{K} D_{i k}}+\sum_{i=1}^{m} \sum_{j=1}^{n} C S_{j} \frac{X_{i j}}{\sum_{k=1}^{K} D_{i k}(2)} \\
\operatorname{Max}_{3}= & \sum_{i=1}^{m} \sum_{j=1}^{n} E_{j} X_{i j},
\end{aligned}
$$




$$
\operatorname{Max} Z_{4}=\sum_{i=1}^{m} \sum_{j=1}^{n} S_{j} X_{i j}
$$

s.t.:

$$
\begin{aligned}
& \sum_{j=1}^{n} X_{i j}=\sum_{k=1}^{K} D_{i k} \quad \forall i \\
& \sum_{j=1}^{n} P P M_{i j} X_{i j} \leq \sum_{k=1}^{K} A P P M_{i} D_{i k} \quad \forall i \\
& \sum_{j=1}^{n} C_{i j} X_{i j} \leq \sum_{k=1}^{K} A C_{i} D_{i k} \quad \forall i, \\
& X_{i j} \geq Y_{i j} L_{i j} \sum_{k=1}^{K} D_{i k} \quad \forall i, j, \\
& X_{i j} \leq C A_{i j} Y_{i j} \quad \forall i, j, \\
& X_{i j} \geq 0 \quad \forall \quad \text { and integer } \quad \forall i, j, \\
& Y_{i j}=0,1 \quad \forall i, j .
\end{aligned}
$$

As it was mentioned, the presented model in this research is multi-product and single-period. Furthermore, it is multi-objective and mixed integer. Such a model needs a multi-objective problem-solving method, which will be given in what follows.

\subsubsection{Solving the mathematical model}

In this study, two methods are presented to solve the multi-objective mathematical model of sustainable supplier selection. They are explained in general terms in the following section.

\section{The augmented $\varepsilon$-constraint method}

The multi-objective mathematical programming method is considered to be an analytical method that is used widely in the domain of multi-objective programming problems. In multi-objective programing problems, there is more than one objective function. Usually, there is no one optimal solution for optimizing all objective functions at the same time. As a consequence, the goal is to find a set of Pareto solutions to the problem. Although each Pareto solution is optimal for one objective function, the given solution will distance at least one of the other objective functions from the optimal amount. The weighted sum method and the epsilon constraint method are two known methods for solving multiobjective programming. The method to solve the multi-objective mathematical model in this research is the augmented $\varepsilon$-constraint method (AUGMECON).
The privilege of the mentioned method is that it generates appropriate Pareto solutions only and avoids ineffective solutions on the other hand. The general form of the multi-objective optimization problem by using this method is as follows [18]:

$$
\begin{aligned}
& \operatorname{Max}\left(f_{1}(x), f_{2}(x), \ldots ., f_{n}(x)\right) \\
& \text { s.t }: x \in S .
\end{aligned}
$$

In the above formula, $S$ represents the allowable range. In order to solve the given model with the epsilon constraint method, initially, one of the objective functions needs to be considered as the main objective function. By considering one of the objective functions each and every time, the problem should be solved and the optimal solutions achieved. Afterwards, except for the main objective function, the other functions must be placed into the constraint method as follows:

$$
\begin{aligned}
& \operatorname{Max}\left(f_{1}(x)+\partial\left(\frac{s_{2}}{r_{2}}+\frac{s_{3}}{r_{3}}+\ldots .+\frac{s_{i}}{r_{i}}+\ldots \frac{s_{n}}{r_{n}}\right)\right) \\
& \text { s.t.: } \\
& \begin{array}{c}
f_{2}(x)-s_{2}=\varepsilon_{2} \\
f_{3}(x)-s_{3}=\varepsilon_{3} \\
\cdot \\
\cdot \\
\cdot \\
f_{n}(x)-s_{n}=\varepsilon_{n} \\
s_{i} \in R^{+} \quad x \in S \quad i \in[2, n] .
\end{array}
\end{aligned}
$$

The optimal solutions of the model are achieved through parametric variables on the right side of the added constraints (epsilons). $r_{i}$ is the variation range of the solutions that result from the $i$ th objective function:

$$
r_{i}=P I S_{f_{i}}-N I S_{f_{i}} .
$$

In the above-mentioned formula, $P I S_{f_{i}}$ is the best solution (positive ideal solution) for the $i$ th objective function, while $N I S_{f_{i}}$ is considered to be the worst solution (negative ideal solution) for the same objective function. Positive and negative ideal solutions for each objective function are the best and worst solutions that result from solving the model through that objective function only-without taking into account the other objective functions. In addition, $\partial$ is a very small number between 0.001 and 0.000001 . $s_{i}$ plays the role of a slack variable corresponding with the $i$ th objective function. If $r_{i}$ is divided into $l_{i}$ equal segments, $l_{i}+1$ different points will ensue. The value of each point can be calculated by the following equation:

$$
\varepsilon_{i}^{\gamma}=N I S_{f_{i}}+\frac{r_{i}}{l_{i}} \times \gamma
$$

where $\gamma$ stands for the point number. This solving method needs to be used for all the vectors of $\varepsilon$. 
Therefore, $\Pi_{i=2}^{n}\left(l_{i}+1\right)$ optimal sub-problems will come into being. Drawing from the above approach and considering the second objective function (non-cost economic criterion) as the main objective function, the problem will change as follows:

$$
\begin{aligned}
\operatorname{Max} Z= & \sum_{i=1}^{m} \sum_{j=1}^{n} D L_{i j} \cdot X_{i j}+\sum_{i=1}^{m} \sum_{j=1}^{n} T_{j} \frac{X_{i j}}{\sum_{k=1}^{K} D_{i k}} \\
& +\sum_{i=1}^{m} \sum_{j=1}^{n} R_{j} \frac{X_{i j}}{\sum_{k=1}^{K} D_{i k}}+\sum_{i=1}^{m} \sum_{j=1}^{n} C O_{j} \frac{X_{i j}}{\sum_{k=1}^{K} D_{i k}} \\
& +\sum_{i=1}^{m} \sum_{j=1}^{n} L R_{j} \frac{X_{i j}}{\sum_{k=1}^{K} D_{i k}}+\sum_{i=1}^{m} \sum_{j=1}^{n} C S_{j} \frac{X_{i j}}{\sum_{k=1}^{K} D_{i k}} \\
& +\partial\left(\frac{s_{1}}{r_{1}}+\frac{s_{3}}{r_{3}}+\frac{s_{4}}{r_{4}}\right),
\end{aligned}
$$

s.t.:

$$
-\sum_{i=1}^{m} \sum_{j=1}^{n} \delta_{i j} X_{i j}-\sum_{i=1}^{m} \sum_{j=1}^{n} g_{i j} X_{i j}-s_{1}=\varepsilon_{1} \quad \forall i, j
$$$$
\sum_{i=1}^{m} \sum_{j=1}^{n} E_{j} X_{i j}-s_{3}=\varepsilon_{3} \quad \forall i, j
$$$$
\sum_{i=1}^{m} \sum_{j=1}^{n} S_{j} X_{i j}-s_{4}=\varepsilon_{4} \quad \forall i, j .
$$

\section{Weighted sum method}

The weighted sum method is one of the methods to solve multi-objective problems. Unlike the epsilon constraint method in which one of the functions will be considered as the main one and the rest will lie in the constraint, in the weighted sum method, the problem will be transformed into a single-objective one and solved accordingly. The general form of a multiobjective mathematical model given in Relation (12) can be reconfigured into a single-objective problem as follows [18]:

$$
\operatorname{Max} \sum_{i=1}^{n} w_{i} f_{i} \text {. }
$$

$w_{i}$ is the relative weight of each of the objective functions. In this method, first and foremost, each of the objective functions will be optimized separately. Then, the negative ideal solution (worst solution) and the positive ideal solution (best solution) will be calculated for each one. Then, the normalized amounts of each objective function will be determined for minimization objective functions and maximization objective func- tions through Eqs. (21) and (22), respectively.

$$
\begin{aligned}
f_{i}^{n} & =\frac{N I S_{f_{i}}-f_{i}}{N I S_{f_{i}}-P I S_{f_{i}}}, \\
f_{i}^{n} & =\frac{f_{i}-N I S_{f_{i}}}{P I S_{f_{i}}-N I S_{f_{i}}} .
\end{aligned}
$$

\section{Total value of sustainable purchasing}

In the aforementioned formulas, PIS and NIS are the best and worst solutions, respectively, that have been obtained for each objective function. After normalizing the objective function, all of them will be transformed into Eq. (23). Accordingly, the final solution will be calculated by solving the mathematical model with one objective.

$$
\operatorname{Max} f=\sum_{i=1}^{n} w_{i} f_{i}^{n}
$$

In order to facilitate the process of decision-making about selecting the best optimal Pareto solutions and comparing the solving methods with one another, the fuzzy approach will be applied as follows [18]. For the minimization objective function, the amount of membership function will be calculated through Eq. (24). In addition, Eq. (25) is used to determine the amount of membership function for the maximization objective function:

$$
\begin{gathered}
\alpha_{i}^{l}= \begin{cases}1 & f_{i}^{l} \leq f_{i}^{\min } \\
\frac{f_{i}^{\max }-f_{i}^{l}}{f_{i}^{\max }-f_{i}^{\min }} & f_{i}^{\min } \leq f_{i}^{l} \leq f_{i}^{\max } \\
0 & f_{i}^{l} \geq f_{i}^{\max }\end{cases} \\
\alpha_{i}^{l}= \begin{cases}1 & f_{i}^{l} \leq f_{i}^{\min } \\
\frac{f_{i}^{\max }-f_{i}^{l}}{f_{i}^{\max }-f_{i}^{\min }} & f_{i}^{\min } \leq f_{i}^{l} \leq f_{i}^{\max } \\
1 & f_{i}^{l} \geq f_{i}^{\max }\end{cases}
\end{gathered}
$$

where $f_{i}^{l}$ stands for the amount of the $i$ th objective function in the $l$ th optimal Pareto solution. Additionally, $\alpha_{i}^{l}$ signifies the amount of $f_{i}^{l}$ membership function. The total amount of membership function for the lth optimal Pareto solution will be calculated through the following formula which, in its own place, shows the total value obtained by solving the model. In Eq. (28), $W_{i}$ represents the relative weight of the objective function, which has been obtained according to the experts' opinions and through AHP method. The solution with the highest amount of TVSP (Total Value of Sustainable Purchasing) will be chosen as the best solution:

$$
T V S P^{l}=\sum_{i=1}^{n} W_{i} \alpha_{i}^{l}
$$




\section{Result, sensitivity analysis, and managerial implications}

Drawing from two solving methods that were explained, the model will be solved and the optimal points will be calculated for both methods. Moreover, the allocation amount to each supplier will be determined for the respective optimal point. It needs to be highlighted that in the epsilon constraint method, $\delta$ is taken to be equal to $0.0001(\delta=0.0001)$, and $l_{i}$ is considered to be 4 for all three constraints. In other words, each variation range $(r)$ is divided into 5 equal segments and, on the whole, 125 sub-problems will follow. Epsilon amount will be calculated for each point and, accordingly, the model will be solved. Pareto solutions are obtained in this stage. Out of 125 solved problems, 88 points are known to be allowable and the rest are non-allowable. The relative weights of objective functions determined according to the judgment of the company's experts on the one hand and through AHP method on the other are given in Table 5. The amounts obtained through the two solving methods are presented in Table 6 . It should be noted that the base for selecting the optimal point is TVSP amount, which needs to be larger.

In the row related to the difference of amounts in the above table, the absolute modulus of the difference of amounts calculated from the two methods and, in the last row, the absolute modulus of the differences are divided by the amounts obtained by the weighted sum method. It can be observed that the solutions obtained by the two solving methods are not significantly different. For the second objective function (maximization of non-cost economic performance) and the social objective function, the results obtained by the epsilon constraint method are considered to be better. Concerning the other objective functions,

Table 5. Relative weights of objective functions obtained by AHP method.

\begin{tabular}{cccc}
\hline Cost & $\begin{array}{c}\text { Non-cost } \\
\text { economic }\end{array}$ & Environmental & Social \\
\hline 0.525 & 0.320 & 0.077 & 0.078 \\
\hline
\end{tabular}

the weighted sum method provided more appropriate solutions. Therefore, the comparison base for the appropriateness of the solving method in the present research is taken to be TVSP amount, which needs to be larger. It must be so because the amounts of all objective functions and their weights are included at the time of calculation. TVSP amount obtained by the weighted sum method is a little more than that by the epsilon constraint method. For that reason, considering the given data in this research and the obtained epsilon amounts, the weighted sum method has provided better results. Accordingly, here, the continuous priority of this method over epsilon constraint method is not implied. Depending on the amounts of parameters and the number of points in the epsilon constraint method, the results will vary in a similar vein. In addition, in the weighted sum method, 8 suppliers (out of 45 suppliers) were not given allocation. By taking into account the difference in the number of allocations in the two solving methods, the amount allocated to 18 suppliers appeared to be equal in the given methods.

In order to analyze the effect of parameter changes on the final results of the mathematical model, the following three cases are taken into consideration:

1. Change of demand parameter in case the other parameters remain constant;

2. Change of the environmental parameter of green design and production in case the other parameters remain constant;

3. Change of the social parameter of work safety and labor health in case the other parameters remain constant.

The results of the above-mentioned cases have been obtained by the weighted sum method. In what follows, they will be compared with the optimal amounts obtained through the main solving process. The results of these three cases are presented in Tables 7-9.

In case of an increase in the parameters of demand, due to the difference of the supply amounts of the given parts, the problem does not have an optimal solution. In case of a ten-percent decrease in the

Table 6. Comparing the amounts of objective functions and TVSP obtained by two solving methods.

\begin{tabular}{|c|c|c|c|c|c|}
\hline Solving method/functions & Cost & Non-cost economic & Environmental & Social & TVSP \\
\hline Epsilon constraint & 4331808.818 & 21207263.322 & 292910.630 & 286607.661 & 0.682 \\
\hline Weighted sum & 4056964.442 & 19335795.71 & 297496.995 & 286455.835 & 0.704 \\
\hline $\begin{array}{l}\text { Absolute value of difference } \\
\text { between two methods }\end{array}$ & 274844.376 & 1871467.612 & 4586.365 & 151.826 & 0.022 \\
\hline Ratio of difference & 0.068 & 0.097 & 0.015 & 0.0005 & 0.031 \\
\hline
\end{tabular}


Table 7. Optimal amounts of the objective function in case of a ten-percent increase/decrease of demand parameters.

\begin{tabular}{cccccc}
\hline Changes $/$ functions & Cost & Non-cost economic & Environmental & Social & TVSP \\
\hline Main model & 4056964.442 & 19335795.71 & 297496.995 & 286455.835 & 0.704 \\
Ten-percent decrease of demand & 3624523.761 & 17509165.05 & 270947.236 & 259699.553 & 0.763 \\
Percent of changes & 10.6 & 9.4 & 8.9 & 9.3 & 8.4 \\
\hline Ten-percent increase of demand & \multicolumn{5}{c}{ Without allowable range } \\
\hline
\end{tabular}

Table 8. Optimal amounts of the objective functions in case of a ten-percent increase/decrease of green design and production parameter.

\begin{tabular}{|c|c|c|c|c|c|}
\hline Changes/functions & Cost & Non-cost economic & Environmental & Social & TVSP \\
\hline Main model & 4056964.442 & 19335795.71 & 297496.995 & 286455.835 & 0.704 \\
\hline $\begin{array}{l}\text { Ten-percent decrease of } \\
\text { environmental parameter }\end{array}$ & 4056964.442 & 19335795.71 & 273012.992 & 286455.835 & 0.611 \\
\hline Percent of changes & 0 & 0 & 8.2 & 0 & 13.2 \\
\hline $\begin{array}{l}\text { Ten-percent increase of } \\
\text { environmental parameter }\end{array}$ & 4056964.442 & 19335795.71 & 321980.997 & 286455.835 & 0.688 \\
\hline Percent of changes & 0 & 0 & 8.2 & 0 & 2.2 \\
\hline
\end{tabular}

Table 9. Optimal amounts of the objective functions in case of a ten-percent increase/decrease of work safety and labor health parameter.

\begin{tabular}{cccccc}
\hline Changes/functions & Cost & Non-cost economic & Environmental & Social & TVSP \\
\hline Main model & 4056964.442 & 19335795.71 & 297496.995 & 286455.835 & 0.704 \\
Ten-percent decrease of social parameter & 4056964.442 & 19335795.71 & 297496.995 & 268924.737 & 0.610 \\
Percent of changes & 0 & 0 & 0 & 6.1 & 13.3 \\
Ten-percent increase of social parameter & 4056964.442 & 19335795.71 & 297496.995 & 303986.932 & 0.688 \\
Percent of changes & 0 & 0 & 0 & 6.1 & 2.2 \\
\hline
\end{tabular}

amounts of demand parameters, it can be observed that the decreasing percentage of the objective functions and TVSP amount are considerably close to the changes of demand parameter.

In case of a change in the environmental parameter, as shown in Table 8, only the amount of the third objective function and, by extension, TVSP amount will change. It is observed that, in both cases, i.e., increasing and decreasing environmental parameters, TVSP decreases compared to the original state. The reason for this is that, according to experts, the weight of the environmental objective function is much lower than that of the economic functions.

Like the former case, as the social parameter changes, only the amount of the fourth objective function and TVSP amount will change. In addition, since the social objective function and the environmental objective function are equal in terms of weight, the amount of changes of TVSP in this case and the former one is equal.

In summary, the presented method in this research can play a helpful role in different organizations in the process of identifying a set of sustainability parameters proportionate with the respective organization. Such parameters can be utilized for evaluating the performance of the organization or its suppliers. Nowadays, large organizations are paying more and more attention to social and environmental issues. Therefore, as one of the most important industries in Iran, the automobile industry should be more sensitive and attentive to these issues. By doing so, the aforementioned industry can raise the quality level of production and move towards sustainable development in society. The proposed model for this research can be considered as a tool for evaluating the sustainability of suppliers in the domain of the automobile industry. 
In the present situation, order allocation to suppliers in the domain of the automobile industry in Iran is not done based on their sustainable performance. Such a phenomenon leaves serious and significant impacts on environment and society both at the moment and in the future. Therefore, it is suggested that Sapco Company as the director of Iran Khodro's supply chain management consider the given criteria in this research and highlight them as influential factors in evaluating the performance of suppliers. By doing so, Sapco Company can improve the performance of its supply chain in economic, social, and environmental fields.

\section{Conclusion}

In the area of supplier selection, two issues are of great importance. Firstly, the selection of criteria and subcriteria were found to pave the ground for evaluating the performance of suppliers as correctly as possible. Secondly, a method was utilized for selecting the best suppliers and determining their order allocation. Both areas were addressed in the present research. After identifying a set of specific criteria and sub-criteria in the case-study industry, an all-inclusive method was presented to evaluate the suppliers' sustainability performance and their order allocation.

In this study, supplier selection in the supply chain of automobile (Sapco Company) was done based on evaluation criteria in three groups, namely economic, social, and environmental. The criteria used in the present study were derived from the cooperation on behalf of experts in the case-study company and through Delphi method. It should be noted that some of the criteria used in this research have not been applied in similar studies so far. PPM, C/100, deviation from the target price, and quality index of supply are among such criteria. Then, 31 parts used to make four types of finished products were selected to conduct this research. These parts are manufactured by 45 suppliers. In order to calculate those parameters for which there was no exact numerical amount, following the judgment of the experts in the case-study company, fuzzy TOPSIS method was utilized. The purpose of the current study is to select the final suppliers and determine their order allocation in a way that the performance of the sustainability of the supply process gets optimized on the whole. In this study, a mathematical model was used to select sustainable suppliers and determine their order allocation. The mathematical model suggested for this research was multi-objective, single-period, and multi-product. In addition, it was multiple in terms of sourcing. The objective functions of the model consisted of minimization of cost, maximization of noncost economic performance, maximization of environmental performance, and maximization of suppliers' social performance. On the other hand, the constraints of the model included demand, capacity, quality, and minimum order amount among others. To solve this model, two methods were utilized: epsilon constraint method and weighted sum method. After solving the model through the two mentioned methods, it was observed that the results obtained from weighted sum method were found to be better based on TVSP. In addition, it was concluded that by changing economic, environmental, and social parameters, one can change the total value of sustainable supply almost with the same proportion.

By taking into account the importance of supplier selection and the increasing attention to the issue of sustainability in recent years, the following topics are suggested for future research and extending sustainable supplier selection problem:

- Considering uncertainty in calculating the parameters of the model, especially demand and capacity;

- Developing a mathematical model to calculate environmental and social criteria in accordance with parts. For example, cases in which carbon emission or pollution caused by manufacturing each product can be measured.

\section{References}

1. Azadnia, A.H., Saman, M.Z.M., Wong, K.Y., Ghadimi, P., and Zakuan, N. "Sustainable supplier selection based on self-organizing map neural network and multi-criteria decision-making approaches", Procedia-Social and Behavioral Sciences, 65, pp. 879884 (2012).

2. Gimenez, C. and Tachizawa, E.M. "Extending sustainability to suppliers: a systematic literature review", Supply Chain Management: An International Journal, 17(5), pp. 531-543 (2012).

3. Hassini, E., Surti, C., and Searcy, C. "A literature review and a case study of sustainable supply chains with a focus on metrics", International Journal of Production Economics, 140(1), pp. 69-82 (2012).

4. Seuring, S. and Müller, M. "From a literature review to a conceptual framework for sustainable supply chain management", Journal of Cleaner Production, 16(15), pp. 1699-1710 (2008).

5. Mahmoudi, A., Sadi-Nezhad, S., and Makui, A. "An extended fuzzy VIKOR for group decision-making based on fuzzy distance to supplier selection", Scientia Iranica, Transactions E, Industrial Engineering, 23(4), pp. 1879-1892 (2016).

6. Rabieh, M., Modarres, M., and Azar, A. "Robust - fuzzy model for supplier selection under uncertainty: an application to the automobile industry", Scientia Iranica, Transactions E, Industrial Engineering, 25(4), pp. 2297-2311 (2018). DOI: $10.24200 /$ sci.2017.4456. 
7. Büyüközkan, G. and Çifçi, G. "A novel fuzzy multicriteria decision framework for sustainable supplier selection with incomplete information", Computers in Industry, 62(2), pp. 164-174 (2011).

8. Rosen, M.A. and Kishawy, H.A. "Sustainable manufacturing and design: Concepts, practices and needs", Sustainability, 4(2), pp. 154-174 (2012).

9. Genovese, A., Lenny Koh, S.C., Bruno, G., and Esposito, E. "Greener supplier selection: state of the art and some empirical evidence", International Journal of Production Research, 51(10), pp. 2868-2886 (2013).

10. Amindoust, A., Ahmed, S., Saghafinia, A., and Bahreininejad, A. "Sustainable supplier selection: A ranking model based on fuzzy inference system", $A p$ plied Soft Computing, 12(6), pp. 1668-1677 (2012).

11. Handfield, R., Walton, S.V., Sroufe, R., and Melnyk, S.A. "Applying environmental criteria to supplier assessment: A study in the application of the analytical hierarchy process", European Journal of Operational Research, 141(1), pp. 70-87 (2002).

12. Lu, L.Y., Wu, C.H., and Kuo, T.C. "Environmental principles applicable to green supplier evaluation by using multi-objective decision analysis", International Journal of Production Research, 45(18), pp. 4317-4331 (2007).

13. Kannan, G. and Vinay, V.P. "Multi-criteria decision making for the selection of CAD/CAM system", International Journal on Interactive Design and Manufacturing, 2(3), pp. 151-159 (2008).

14. Kuo, R.J., Wang, Y.C., and Tien, F.C. "Integration of artificial neural network and MADA methods for green supplier selection", Journal of Cleaner Production, 18(12), pp. 1161-1170 (2010).

15. Bai, C. and Sarkis, J. "Integrating sustainability into supplier selection with grey system and rough set methodologies", International Journal of Production Economics, 124(1), pp. 252-264 (2010).

16. Punniyamoorthy, M., Mathiyalagan, P., and Parthiban, P. "A strategic model using structural equation modeling and fuzzy logic in supplier selection", Expert Systems with Applications, 38(1), pp. $458-474$ (2011).

17. Govindan, K., Khodaverdi, R., and Jafarian, A. "A fuzzy multi criteria approach for measuring sustainability performance of a supplier based on triple bottom line approach", Journal of Cleaner Production, 47, pp. 345-354 (2013).

18. Azadnia, A.H., Saman, M.Z.M., and Wong, K.Y. "Sustainable supplier selection and order lot-sizing: an integrated multi-objective decision-making process", International Journal of Production Research, 53(2), pp. 383-408 (2015).

19. Bai, C. and Sarkis, J. "Determining and applying sustainable supplier key performance indicators", Supply Chain Management: An International Journal, 19(3), pp. 275-291 (2014).
20. Azadi, M., Jafarian, M., Saen, R.F., and Mirhedayatian, S.M. "A new fuzzy DEA model for evaluation of efficiency and effectiveness of suppliers in sustainable supply chain management context", Computers \& Operations Research, 54, pp. 274-285 (2015).

21. Sarkis, J. and Dhavale, D.G. "Supplier selection for sustainable operations: A triple-bottom-line approach using a Bayesian framework", International Journal of Production Economics, 166, pp. 177-191 (2015).

22. Orji, I. and Wei, S. "A decision support tool for sustainable supplier selection in manufacturing firms", Journal of Industrial Engineering and Management, 7(5), pp. 1293-1315 (2014).

23. Yousefi, S., Shabanpour, H., Fisher, R., and Saen, R.F. "Evaluating and ranking sustainable suppliers by robust dynamic data envelopment analysis", Measurement, 83, pp. $72-85$ (2016).

24. Luthra, S., Govindan, K., Kannan, D., Mangla, S.K., and Garg, C.P. "An integrated framework for sustainable supplier selection and evaluation in supply chains", Journal of Cleaner Production, 140, pp. 16861698 (2017).

25. Fallahpour, A., Olugu, E.U., Musa, S.N., Wong, K.Y., and Noori, S. "A decision support model for sustainable supplier selection in sustainable supply chain management", Computers \& Industrial Engineering, 105, pp. 391-410 (2017).

26. Ghadimi, P., Dargi, A., and Heavey, C. "Sustainable supplier performance scoring using audition checklist based fuzzy inference system: a case application in automotive spare part industry", Computers \& Industrial Engineering, 105, pp. 12-27 (2017).

27. Mousakhani, S., Nazari-Shirkouhi, S., and BozorgiAmiri, A. "A novel interval type-2 fuzzy evaluation model based group decision analysis for green supplier selection problems: A case study of battery industry", Journal of Cleaner Production, 168, pp. 205-218 (2017).

28. Seuring, S. "A review of modeling approaches for sustainable supply chain management", Decision Support Systems, 54(4), pp. 1513-1520 (2013).

29. Keskin, G.A., İlhan, S., and Özkan, C. "The Fuzzy ART algorithm: A categorization method for supplier evaluation and selection", Expert Systems with Applications, 37(2), pp. 1235-1240 (2010).

30. Aliakbari, A. and Seifbarghy, M. "A supplier selection model for social responsible supply chain", Journal of Optimization in Industrial Engineering, 8, pp. 41-53 (2011).

31. Su, C.M., Horng, D.J., Tseng, M.L., Chiu, A.S., Wu, K.J., and Chen, H.P. "Improving sustainable supply chain management using a novel hierarchical greyDEMATEL approach", Journal of Cleaner Production, 134, pp. 469-481 (2016).

32. Trapp, A.C. and Sarkis, J. "Identifying Robust portfolios of suppliers: a sustainability selection and development perspective", Journal of Cleaner Production, 112, pp. 2088-2100 (2016). 
33. Mafakheri, F., Breton, M., and Ghoniem, A. "Supplier selection-order allocation: A two-stage multiple criteria dynamic programming approach", International Journal of Production Economics, 132(1), pp. 52-57 (2011).

34. Shaw, K., Shankar, R., Yadav, S.S., and Thakur, L.S. "Supplier selection using fuzzy AHP and fuzzy multiobjective linear programming for developing low carbon supply chain", Expert Systems with Applications, 39(9), pp. 8182-8192 (2012).

35. Afshar Bakeshlou, E., Arshadi Khamse, A., Goudarzian Asl, M.A., and Sadeghi, J. "Evaluating a green supplier selection problem using a hybrid MODM algorithm", Journal of Intelligent Manufacturing, 28(4), pp. 913-927 (2017).

36. Nazari-Shirkouhi, S., Shakouri, H., Javadi, B., and Keramati, A. "Supplier selection and order allocation problem using a two-phase fuzzy multi-objective linear programming", Applied Mathematical Modelling, 37(22), pp. 9308-9323 (2013).

37. Kannan, D., Khodaverdi, R., Olfat, L., Jafarian, A., and Diabat, A. "Integrated fuzzy multi criteria decision making method and multi-objective programming approach for supplier selection and order allocation in a green supply chain", Journal of Cleaner Production, 47, pp. 355-367 (2013).

38. Windle, P.E. "Delphi technique: assessing component needs", Journal of PeriAnesthesia Nursing, 19(1), pp. 46-47 (2004).

39. Keeney, S., McKenna, H., and Hasson, F., The Delphi Technique in Nursing and Health Research, John Wiley \& Sons (2010).

\section{Biographies}

Masood Rabieh received his $\mathrm{PhD}$ from Tarbiat Modaress University, Iran. $\mathrm{He}$ is an Assistant Professor at the Department of Industrial Management at Shahid Beheshti University, Iran. His research interests include operations research, system dynamics \& systems thinking, supply chain management and project management.

Abbas Fadaei Rafsanjani first studied Business Management at the University of Shahid Bahonar in Kerman province. Then, he studied at Shahid Beheshti University, Tehran, where he received an MA Industrial Management degree. His research interests and publication lie in the field of project management and optimization. He has contributed articles to the International Journal of Advanced Manufacturing Technology.

Leila Babaee is a PhD student in Industrial Management (production and operation) at the Department of Industrial Management at Shahid Beheshti University, Iran. Her research studies include sustainability in supply chain, supply chain management, and supply chain network design.

Mahdi Esmaeili is a PhD student in Industrial Management (production and operation) at the Department of Industrial Management in Allameh Tabataba'i University, Tehran, Iran, He is the Head of Logistics Engineering in Supplying Automative Parts CO, Iran. His research interests include logistics, supply chain management, transportation, and lean production. 